\title{
Cytogenetic and cytometric analyses in artificial intercytotypic hybrids of the emergent orchid model species Erycina pusilla
}

\author{
Hsuan-Yu Yeh $\cdot$ Choun-Sea Lin • \\ Song-Bin Chang $\mathbb{D}$
}

Received: 19 March 2015/ Accepted: 9 August 2015/Published online: 3 September 2015

(C) The Author(s) 2015. This article is published with open access at Springerlink.com

\begin{abstract}
Erycina pusilla is considered a potential model organism for orchids, because of several advantageous features, such as short juvenile period, low chromosome number and all year round blooming. Two different chromosome numbers $(2 \mathrm{n}=10$ and $2 \mathrm{n}=12$ ) are reported for E. pusilla, which suggests two cytotypes. To reveal the genome homology between these two cytotypes, we generated hybrids from the intercytotypic reciprocal crosses $(2 \mathrm{n}=10 \times 2 \mathrm{n}=12$ and $2 \mathrm{n}=12 \times 2 \mathrm{n}=10)$, and applied 4',6-diamidino-2-phenylindole staining, genomic in situ hybridization and flow cytometry for genomic and cytogenetic analysis. The parental genomes showed high similarity both in genomic composition and content. The hybrids displayed a chromosome number of $2 \mathrm{n}=11$ in mitotic cells. Moreover, five bivalents and one univalent were observed at meiotic metaphase I stage. We observed meiotic synaptic behavior and found homeologous pairing with unpaired loops between parental chromosome pairing segments. These results demonstrated that chromosome rearrangement events have occurred between parental cytotypes during evolution. This
\end{abstract}

H.-Y. Yeh · S.-B. Chang $(\bowtie)$

Department of Life Sciences, National Cheng Kung

University, Tainan 701, Taiwan

e-mail: sbchang@mail.ncku.edu.tw

C.-S. Lin

Agricultural Biotechnology Research Center, Academia

Sinica, Taipei 115, Taiwan study also illustrated the genome homology and homeologous pairing at pachytene phase, indicating that the chromosome number variation of two cytotypes mainly resulted from chromosome rearrangements, not changes in genomic constitution.

Keywords Chromosome rearrangements . Cytotype $\cdot$ Erycina pusilla $\cdot$ Intercytotypic hybrids

\section{Introduction}

The orchid Erycina pusilla is an epiphytic Oncidiinae species, which is widespread in the wild and has been recorded from the Caribbean, Mesoamerica and South America. Karyotype analysis in the Orchidaceae revealed a wide range of chromosome numbers, and this diversity has been employed to evaluate evolutionary relationships and taxonomic divisions (Felix and Guerra 2000, 2005, 2010). E. pusilla has several advantageous features, such as a relatively small genome size (1.5 pg/1C, Chase et al. 2005), low chromosome number $(2 \mathrm{n}=10$, Felix and Guerra 2000 or $2 n=12$, Felix and Guerra 1999, 2010), short generation time (less than 1 year), tiny adult plant (less than $10 \mathrm{~cm}$ in height at maturity) and all year blooming, which makes it a good potential model species in the Orchidaceae, one of the largest flowering families. However, variable chromosome complements of $2 n=10$ and $2 n=12$ are reported for this species, and it is rare for a species to present more than 
one cytotype. Natural cytotypes in a species can be at different ploidy levels; e.g., polyploidy, aneuploidy, or dysploidy. Our collected cytotypes of E. pusilla could be either aneuploid or dysploid.

To reveal the genomic similarity between the two cytotypes, we made artificial reciprocal crosses between them $(2 \mathrm{n}=10 \times 2 \mathrm{n}=12$ and $2 \mathrm{n}=12 \times 2 \mathrm{n}=10$ ), and analyzed the karyotype characteristics, genomic composition and content, and chromosome pairing of the progeny using 4',6diamidino-2-phenylindole (DAPI) staining, genomic in situ hybridization (GISH) and flow cytometry (FCM). DAPI is a fluorescent dye that has been used extensively to observe chromosomes and highlight heterochromatin bands for karyotype analysis (Kim et al. 2002).

GISH is an effective method to determine parental genome constitution and is used widely to identify interspecific and intergeneric hybrids of various species (Ji et al. 2004; Lee et al. 2011; Lin et al. 2005; Nakazawa et al. 2011; Navabi et al. 2011; Yao et al. 2010). Furthermore, the use of blocking DNA can provide better differentiation of parental genome homology (Anamthawat-Jónsson et al. 1990; Tang et al. 2010). Genomes sharing less homology can be discriminated by GISH (Schwarzacher et al. 1989), while closely-related parental chromosome sets would be indistinguishable because of their similar genome constitutions (Lin et al. 2005).

Meiotic behavior can be observed during pollen development of hybrids and homologous chromosome pairing should be carried out to ensure normal chromosome disjunction and segregation. Meiosis at both the pachytene and metaphase stages can provide reliable information of genomic similarity according to chromosome pairing affinity (Gatt et al. 2000).

FCM measures genome size by analyzing and comparing fluorescent intensities with reference standards. FCM assays have been used to discriminate related taxa with same chromosome number in many species (Bennett et al. 2000; Greilhuber 2005; Murray 2005), and have analyzed the genome constitution of hybrids (Amano et al. 2007, 2009; Nakazawa et al. 2011). In the present study, we used the abovementioned cytogenetic techniques to analyze genome homology by generating intercytotypic hybrids, and for observing their meiotic behavior. The results demonstrated the genomic similarity and viabilities among the parental species and the hybrids of $E$. pusilla at the cyto-molecular level.

\section{Materials and methods}

Plant material and artificial crossing

Two populations $(2 \mathrm{n}=10$ and $2 \mathrm{n}=12)$ of E. pusilla were obtained originally from two South American countries, separately $(2 n=10$ from Ecuador and $2 n=12$ from Suriname). We deposited specimens in an internationally accessible herbarium, Taiwan's National Museum of Natural Science (Taichung city, Taiwan; website: http://www.nmns.edu.tw/index eng.html); voucher number TNM S182271 for $2 \mathrm{n}=10$ and TNM S182272 for $2 \mathrm{n}=12$. Two populations $(2 n=10$ and $2 n=12)$ were examined for chromosome number and six individuals of each population were artificially self-pollinated. In addition, artificial reciprocal crosses between the two cytotypes were made using seven different parental pairs. Seeds from successful setting fruits were sown and plantlets were cultivated on half-strength Murashige and Skoog (1962) medium under sterile conditions.

Chromosome slide preparation

Fresh root tips were excised and pre-treated with $2 \mathrm{mM}$ 8-hydroxyquinolino (a spindle inhibitor) at $15^{\circ} \mathrm{C}$ for $2 \mathrm{~h}$. After the inhibition treatment, root tips were fixed by freshly prepared Carnoy's fixative (three parts $95 \%$ ethanol, one part $100 \%$ glacial acetic acid) at $4{ }^{\circ} \mathrm{C}$ for storage. Anthers less than $0.6 \mathrm{~mm}$ in diameter were collected, fixed and stored in Carnoy's solution for further use. Fixed material (root tips or anthers) was washed with distilled water to remove the fixative. Tissues were digested with an enzyme mixture (1\% (w/v) cellulose Onozuka RS (Yakult Honsha, Tokyo, Japan), $1 \%$ (w/v) pectolyase Y23, $1 \%(\mathrm{w} / \mathrm{v})$ pectinase solution) in a humid container at $37{ }^{\circ} \mathrm{C}$ for $80 \mathrm{~min}$. Preparations were squashed in a drop of $45 \%$ acetic acid and frozen in liquid nitrogen. The coverslips were removed using a razor blade. Chromosome slides were sequentially rinsed with Carnoy's solution and $95 \%$ ethanol, dried in air and stored at $-20{ }^{\circ} \mathrm{C}$. 
Probe labeling, GISH, and fluorescence in situ hybridization (FISH)

Genomic DNA was extracted from young flowers using the urea extraction buffer system (Sheu et al. 1996). Specific-genomic DNA probes were either labeled with Digoxigenin-11-dUTP or Biotin-16dUTP generated by nick translation (Roche, Basel, Switzerland). Genomic DNA for unlabeled blocking was obtained by sonication, yielding DNA fragments of $100-500 \mathrm{bp}$. For GISH, pre-hybridization treatments included RNase A $(5 \mu \mathrm{g} / \mathrm{ml})$, pepsin $(5 \mu \mathrm{g} / \mathrm{ml})$ and $4 \%$ formaldehyde solution. The hybridization mixture (50 ng labeled-probes of one parent genomic DNA, with genomic blocking DNA from the other parent at concentration of 100 -fold that of the probe DNA for a competitive GISH experiment, $50 \%$ formamide, $10 \%$ sodium dextran sulfate, $0.25 \%$ SDS and $2 \times$ SSC) was denatured at $100{ }^{\circ} \mathrm{C}$ for $10 \mathrm{~min}$, cooled on ice for $5 \mathrm{~min}$ and transferred to chromosome slides. Hybridization reactions were carried out in a humid chamber at $37{ }^{\circ} \mathrm{C}$ for 16-20 h. The slides were washed by $50 \%$ formamide in $2 \times \mathrm{SSC}$ at $42{ }^{\circ} \mathrm{C}$ and antibodies (streptavidin or anti-DIG conjugated florescent dye) were applied at $37^{\circ} \mathrm{C}$ for $1 \mathrm{~h}$. Un-conjugated antibodies were removed by washing with $2 \times$ SSC and the slides were dehydrated through an ethanol series (70, 90, $100 \%)$. Twelve microliters of Vectashield (Vector Laboratories, Burlingame, CA, USA) including $5 \mu \mathrm{g} /$ $\mathrm{ml}$ of DAPI were mounted on slides and covered with $24 \times 50 \mathrm{~mm}$ coverslips. Fluorescent patterns were observed and captured under a fluorescence microscope equipped with a digital camera. Images were analyzed using AxioVision and ImagePlus image processing software. 45S rDNA (ribosomal DNA) genes are found in all eukaryotes and are arranged in tandem arrays of repeat units; therefore, we used the $45 \mathrm{~S}$ rDNA gene as a chromosome marker to provide large signals in fluorescence in situ hybridization (FISH). FISH of the 45S rDNA gene was performed according to Chang et al. (2008).

Flow cytometry

Plant nuclei were isolated from flower labellum tissues. Approximately $50 \mathrm{mg}$ of fresh material were chopped with a razor blade in a $5 \times 5$ Petri dish containing $1 \mathrm{ml}$ of Tris- $\mathrm{MgCl}_{2}$ buffer (200 mM Tris,
$4 \mathrm{mM} \mathrm{MgCl}{ }_{2} \cdot 6 \mathrm{H}_{2} \mathrm{O}, 0.5 \%$ (v/v) Triton X-100, $\mathrm{pH}$ $7.5)$ and $20 \mu \mathrm{g} / \mathrm{ml}$ propidium iodide. Nuclear suspensions were filter twice through a $30-\mu$ m nylon mesh, and kept on ice. Samples were loaded onto the MoFlo XDP Cell Sorter flow cytometry (Beckman Coulter, Brea, CA, USA) and excited with a $488 \mathrm{~nm}$ argon laser. Chicken erythrocyte nuclei (2C DNA content $=3.01 \mathrm{pg}$; Johnston et al. 1999), were used as reference standard for the two cytotypes of E. pusilla. The genome size was estimated according to the following formula: DNA content $(\mathrm{pg} / 2 \mathrm{C})=($ sample peak mean $\times$ DNA content of reference standard)/ (reference standard peak mean).

\section{Results}

Artificial intercytotypic- and self-hybridization

The capsule set rates of $2 \mathrm{n}=10 \times 2 \mathrm{n}=12$ and $2 \mathrm{n}=12 \times 2 \mathrm{n}=10$ were 57.14 and $28.57 \%$, respectively. Moreover, the crosses showed similar fruit set rates to the self-pollinated maternal plants (Table 1). Seeds of successful crosses were fertile and plantlets presented similar growth patterns to the selfed parental plants.

Chromosome counts and characterization

Somatic metaphase chromosome numbers of the parental plants and intercytotypic hybrids were $2 \mathrm{n}=10$ (Fig. 1a), $2 \mathrm{n}=12$ (Fig. 1c) and $2 \mathrm{n}=11$ (Fig. 1b), respectively. The three chromosome sets all revealed asymmetric karyotypes, with dominance of metacentric or submetacentric chromosomes. The slight differences in chromosome morphology observed (length, width and brightness of heterochromatin) among the cytotypes reflected different levels of chromosome condensation, caused by an asynchronous metaphase stage.

Genome analysis of intercytotypic hybrids

GISH was performed on the hybrids using a probe from one parental genomic DNA in the presence or absence of blocking DNA from the other parent. Chromosome sets individually hybridized with genomic DNA either from $2 \mathrm{n}=10$ (Fig. $2 \mathrm{a}$ ) or $2 \mathrm{n}=12$ (Fig. 2b); both showed strong hybridization signals spread all over the 
Table 1 Artificial pollination percentage of self-pollinated plants and intercytotypic hybrids

\begin{tabular}{llll}
\hline Species & Number of pollinations & $\begin{array}{l}\text { Number of successful } \\
\text { fruit set }\end{array}$ & $\begin{array}{l}\text { Percentage of successful } \\
\text { fruit set (\%) }\end{array}$ \\
\hline $2 n=10 \otimes$ & 6 & 3 & 50 \\
$2 n=10 \times 2 n=12$ & 7 & 4 & 57.14 \\
$2 n=12 \otimes$ & 6 & 2 & 33.33 \\
$2 n=12 \times 2 n=10$ & 7 & 2 & 28.57 \\
\hline
\end{tabular}

$\otimes$ indicates a selfing cross
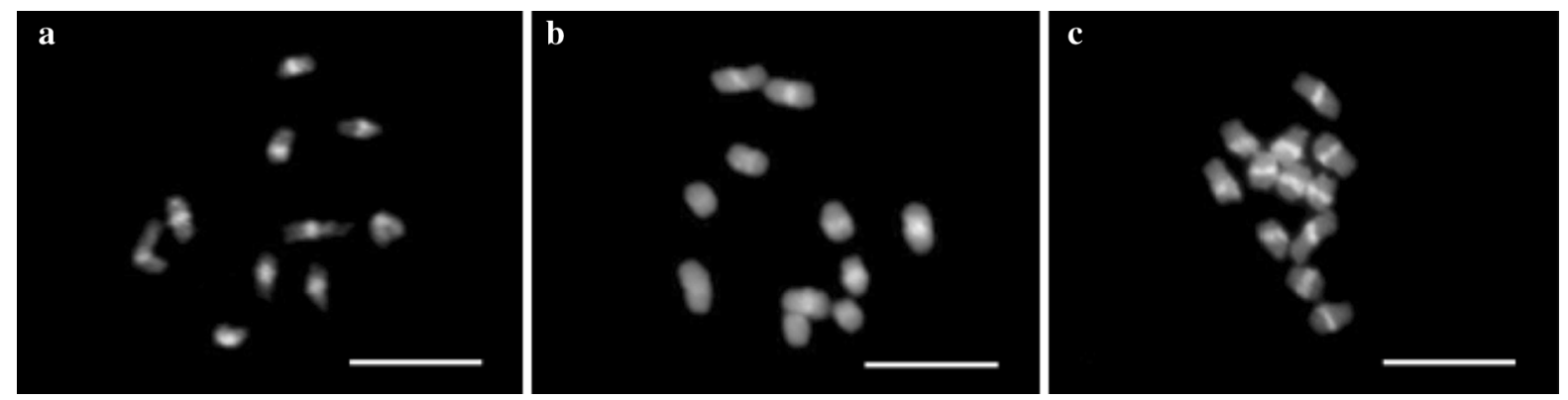

Fig. 1 DAPI-stained mitotic metaphase chromosomes: $\mathbf{a}$ one parental cytotype, $2 \mathrm{n}=10$, $\mathbf{b}$ intercytotypic hybrids, $2 \mathrm{n}=11$ and $\mathbf{c}$ the other parental cytotype, $2 \mathrm{n}=12$. Bars represent $10 \mu \mathrm{m}$

chromosomes under conditions lacking blocking DNA. By contrast, genomic DNA signals vanished when the blocking DNA was added (Fig. 2c, d). The data revealed high similarity and homology in genome composition between the parental genomes. Conversely, FCM analysis of $2 \mathrm{n}=10,2 \mathrm{n}=11$ and $2 \mathrm{n}=12$ revealed genome sizes of $6.02 \pm 0.08$, $5.95 \pm 0.19$ and $5.51 \pm 0.09 \mathrm{pg}, \quad$ respectively (Table 2). The three cytotypes showed close genomic contents, whose values slightly diminished as the chromosome number increased.

Chromosome pairing affinity in intercytotypic hybrids

In intercytotypic hybrids of $2 \mathrm{n}=10 \times 2 \mathrm{n}=12$ and $2 \mathrm{n}=12 \times 2 \mathrm{n}=10$, chromosome pairing showed five bivalents and one univalent at meiotic metaphase I stage (Fig. 3). In addition, one pair of $45 \mathrm{~S}$ rDNA signals was detected on the terminal sites of a bivalent. Figure 4 revealed the homeologous pairing condition of the pachytene chromosome sets and the part of the chromosomes were not perfectly paired, which generated unpaired loops between paired chromosome segments. An ideogram was drawn to provide an illustration of the meiotic chromosome pairing affinity in the hybrids.

\section{Discussion}

Artificial intercytotypic reciprocal crosses

In E. pusilla, the fertilization ability possibly depends on the maternal species rather than the paternal species based on the fruit set rates in this study. Furthermore, cytotype $2 \mathrm{n}=10$ showed a higher successful fruit set rate than $2 \mathrm{n}=12$; however, the causes and mechanisms remain unclear. In addition, the somatic chromosome number of intercytotypic hybrids showed $2 \mathrm{n}=11$, representing true hybrids generated from fused zygotes of gametes of $n=5$ and $n=6$ from two cytotypic parents.

Genome similarity between parental plants

The chromosome sets of intercytotypic hybrids hybridized with genomic DNA of the $2 \mathrm{n}=10$ and $2 \mathrm{n}=12$ plants, with or without blocking DNA, showed almost identical patterns in the GISH experiments (Fig. 2). This result not only revealed similar genome constitution, especially in repetitive DNA sequences between two cytotypes, but also implied that the change in chromosome number must have occurred recently and too little time has past for the repetitive elements to have diverged. In addition, the genome size 

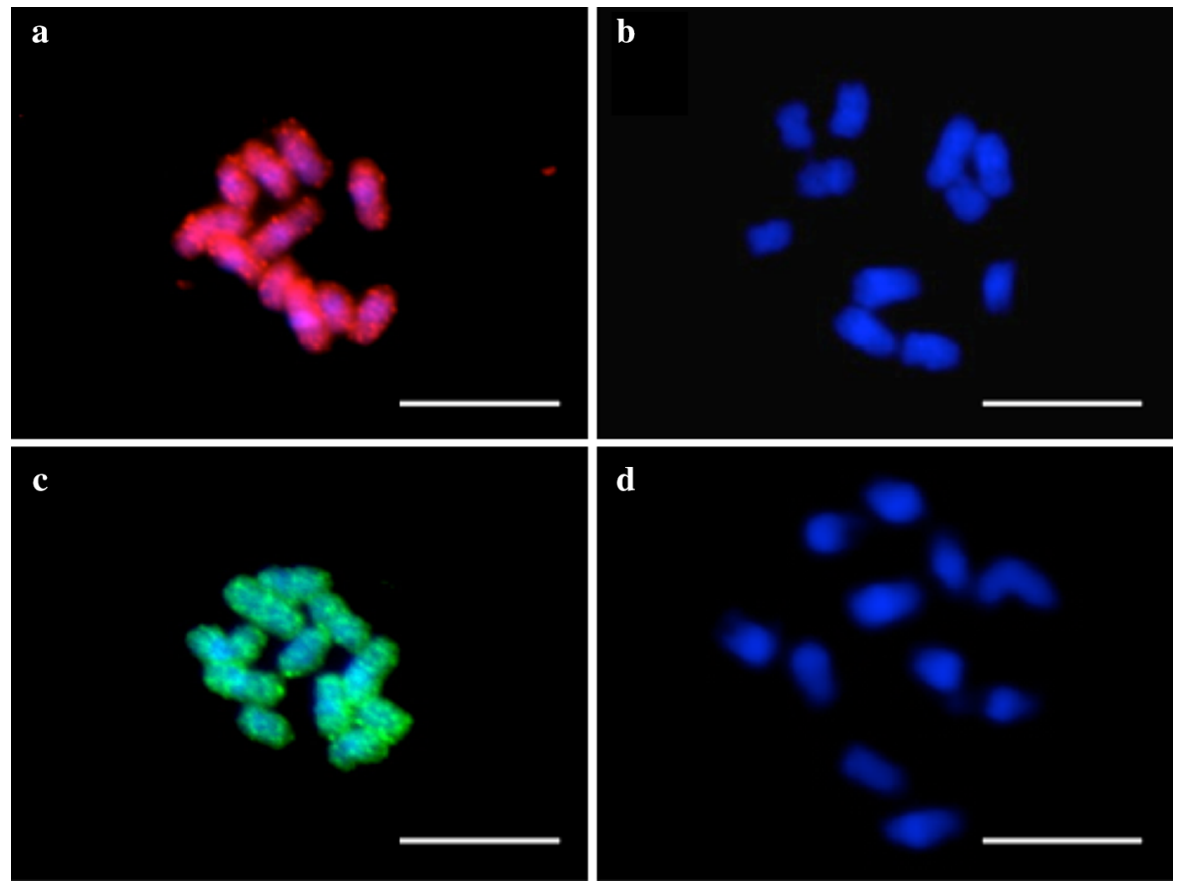

Fig. 2 Genomic in situ hybridization in intercytotypic hybrids. Mitotic chromosomes were counterstained with DAPI and merged with genomic signals from one parent in the presence or absences of blocking DNA from the other parent. Hybrid chromosomes hybridized with $2 n=10$ genomic DNA in the

absence of blocking DNA (a) and in the presence of blocking DNA (b). Hybrid chromosomes hybridized with $2 \mathrm{n}=12$ genomic DNA in the absence of blocking DNA (c) and in the presence of blocking DNA (d). Bars represent $10 \mu \mathrm{m}$
Table 2 Genome size analysis by flow cytometry

\begin{tabular}{lll}
\hline & $\begin{array}{l}\text { Chromosome } \\
\text { number }(2 \mathrm{n})\end{array}$ & $\begin{array}{l}\text { Nuclear DNA content } \\
(\mathrm{pg} / 2 \mathrm{C})\end{array}$ \\
\hline Parental strain & $2 \mathrm{n}=10$ & $6.02 \pm 0.08$ \\
Intraspecific F1 hybrid & $2 \mathrm{n}=11$ & $5.95 \pm 0.19$ \\
Parental strain & $2 \mathrm{n}=12$ & $5.51 \pm 0.09$ \\
\hline
\end{tabular}
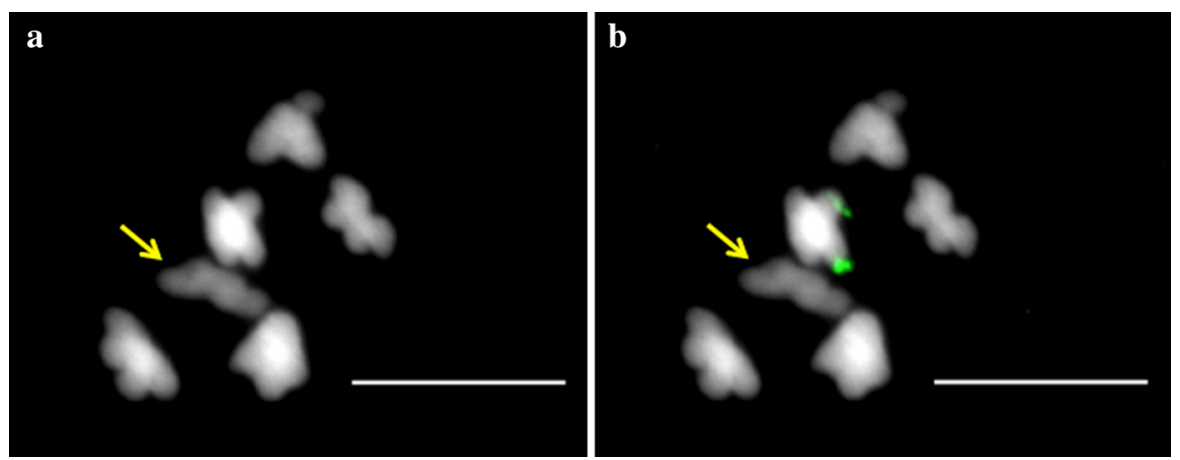

Fig. 3 Meiotic chromosome pairings in an intercytotypic hybrid revealed by DAPI counterstaining. Five bivalents and one univalent (arrow) are shown in a chromosome set, and a pair of $45 \mathrm{~S}$ rDNA signals (green, b) are located on a bivalent. Bars represent $10 \mu \mathrm{m}$

analysis among three cytotypes showed that the values slightly decreased as the chromosome number increased. Therefore, we hypothesized that the chromosome number variation event was caused by chromosomal rearrangement, which suggested dysploidy. A previous study of the orchid genus 
Fig. 4 Meiotic behavior of intercytotypic hybrids. Figure shows homeologous pairing (yellow circle) at the pachytene stage, and the ideogram demonstrates chromosome pairing segments and the unpaired loop. Bars represent $10 \mu \mathrm{m}$

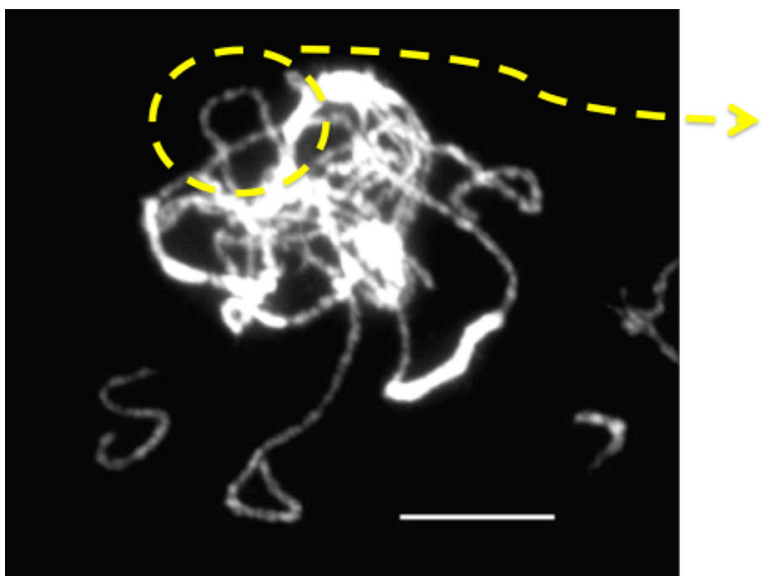

Paphiopedilum demonstrated that the increase in genome size was positively correlated with chromosome number (Leitch et al. 2009), which is the reverse of that observed in E. pusilla. Genome size has been suggested to have a distinct relationship with cell size and generation time (Bennett and Smith 1976; Cavalier-Smith 1978, 2005), and seems to be less related with chromosome number (Chase et al. 2005). The variation in genome size causes no difference in gene number, but does cause divergence in the quantity of repetitive DNA sequences (Flavell et al. 1974, 1977; Leitch et al. 2009). E. pusilla is placed in the Cymbidioid group, which suggested that the most probable basic chromosome number for this group is $x=7$ (Felix and Guerra 2000, 2005, 2010). Moreover, the haploid chromosome number in the genus Erycina, previously called Psygmorchis Dodson and Dressler, was found to vary between $2 \mathrm{n}=10,12$ and 14 (Felix and Guerra 2000). Therefore, the change in chromosome number is apparently from 12 to 10 , and possibly initially from 14 . If this hypothesis is true, chromosome fusion events must have occurred in the past, which supports our hypothesis that the chromosome number variation event was merely caused by chromosomal rearrangement, which suggests dysploidy.

Chromosome pairing in intercytotypic hybrids

The chromosome pairing of hybrids at meiotic metaphase I stage showed five bivalents and one univalent, which corresponded to the somatic mitotic results with chromosome number of $2 \mathrm{n}=11$ (Figs. 1, 2, 3). Meiotic behavior at the pachytene stage showed homeologous pairing, displaying chromosome pairing segments accompanied by unpaired chromosome regions and loops. The parental plants revealed high homology in their genome constitutions (Fig. 2). Homeologous chromosome pairing may be caused by chromosomal rearrangements (Datson and Murray 2006; Moscone et al. 2007), resulting in changes in the order and location of genes or DNA segments. In this study, the intercytotypic hybrids were produced to demonstrate genome homology and similar genome contents to the parental species. The results demonstrated that chromosome rearrangements have occurred between parental cytotypes, but not changes in genomic constitution.

Acknowledgments This research was supported by Ministry of Science and Technology, Taiwan, R.O.C. under Grant No. 104-2313-B-006-001.

Open Access This article is distributed under the terms of the Creative Commons Attribution 4.0 International License (http:// creativecommons.org/licenses/by/4.0/), which permits unrestricted use, distribution, and reproduction in any medium, provided you give appropriate credit to the original author(s) and the source, provide a link to the Creative Commons license, and indicate if changes were made.

\section{References}

Amano J, Kuwayama S, Mizuta Y, Oomiya T, Nakamura T, Nakano M (2007) Early identification of intra- and intergeneric hybrids among colchicaceous ornamentals, Gloriosa spp., Littonia modesta Hook. and Sandersonia aurantiaca Hook., by flow cytometry and random amplified polymorphic DNA analyses. J Jpn Soc Hortic Sci 76:73-78

Amano J, Nakazawa D, Kuwayama S, Mizuta Y, Okuno H, Watanabe Y, Godo T, Han DS, Nakano M (2009) 
Intergeneric hybridization among colchicaceous ornamentals, Gloriosa spp., Littonia modesta and Sandersonia aurantiaca via ovule culture. Plant Biotechnol 26:535-541

Anamthawat-Jónsson K, Schwarzacher T, Leitch A, Bennett M, Heslop-Harrison J (1990) Discrimination between closely related Triticeae species using genomic DNA as a probe. Theor Appl Genet 79:721-728

Bennett MD, Smith J (1976) Nuclear DNA amounts in angiosperms. Philos Trans R Soc Lond B, Biol Sci 274:227-274

Bennett MD, Johnston S, Hodnett GL, Price HJ (2000) Allium cepa L. cultivars from four continents compared by flow cytometry show nuclear DNA constancy. Ann Bot 85:351-357

Cavalier-Smith T (1978) Nuclear volume control by nucleoskeletal DNA, selection for cell volume and cell growth rate, and the solution of the DNA C-value paradox. J Cell Sci 34:247-278

Cavalier-Smith T (2005) Economy, speed and size matter: evolutionary forces driving nuclear genome miniaturization and expansion. Ann Bot 95:147-175

Chang SB, Yang TJ, van Vugt J, Vosman B, Kuipers A, Wennekes J, Wing R, Jacobsen E, de Jong H (2008) FISH mapping and molecular organization of the major repetitive sequences of tomato. Chromosome Res 16:919-933

Chase MW, Hanson L, Albert VA, Whitten WM, Williams NH (2005) Life history evolution and genome size in subtribe Oncidiinae (Orchidaceae). Ann Bot 95:191-199

Datson PM, Murray BG (2006) Ribosomal DNA locus evolution in Nemesia: transposition rather than structural rearrangement as the key mechanism? Chromosome Res $14: 845-857$

Felix LP, Guerra M (1999) Chromosome analysis in Psygmorchis pusilla (L.) Dodson \& Dressler: the smallest chromosome number known in Orchidaceae. Caryologia 52:165-168

Felix LP, Guerra M (2000) Cytogenetics and cytotaxonomy of some Brazilian species of Cymbidioid orchids. Genet Mol Biol 23:957-978

Felix LP, Guerra M (2005) Basic chromosome numbers of terrestrial orchids. Plant Syst Evol 254:131-148

Felix LP, Guerra M (2010) Variation in chromosome number and the basic number of subfamily Epidendroideae (Orchidaceae). Bot J Linn Soc 163:234-278

Flavell R, Bennett M, Smith J, Smith D (1974) Genome size and the proportion of repeated nucleotide sequence DNA in plants. Biochem Genet 12:257-269

Flavell RB, Rimpau J, Smith DB (1977) Repeated sequence DNA relationships in four cereal genomes. Chromosoma 63:205-222

Gatt M, Hammett K, Murray B (2000) Interspecific hybridization and the analysis of meiotic chromosome pairing in Dahlia (Asteraceae-Heliantheae) species with $\mathrm{x}=6$. Plant Syst Evol 221:25-33

Greilhuber J (2005) Intercytotypic variation in genome size in angiosperms: identifying its existence. Ann Bot 95:91-98
Ji YF, Pertuze R, Chetelat RT (2004) Genome differentiation by GISH in interspecific and intergeneric hybrids of tomato and related nightshades. Chromosome Res 12:107-116

Johnston JS, Bennett MD, Rayburn AL, Galbraith DW, Price HJ (1999) Reference standards for determination of DNA content of plant nuclei. Am J Bot 86:609-613

Kim ES, Punina EO, Rodionov AV (2002) Chromosome CPD(PI/DAPI)- and CMA/DAPI-banding patterns in $\mathrm{Al}$ lium cepa L. Russ J Genet 38:392-398

Lee YI, Chang FC, Chung MC (2011) Chromosome pairing affinities in interspecific hybrids reflect phylogenetic distances among lady's slipper orchids (Paphiopedilum). Ann Bot 108:113-121

Leitch I, Kahandawala I, Suda J, Hanson L, Ingrouille MJ, Chase M, Fay M (2009) Genome size diversity in orchids: consequences and evolution. Ann Bot 104:469-481

Lin CC, Chen YH, Chen WH, Chen CC, Kao YY (2005) Genome organization and relationships of Phalaenopsis orchids inferred from genomic in situ hybridization. Bot Bull Acad Sin 46:339-345

Moscone EA, Samuel R, Schwarzacher T, Schweizer D, Pedrosa-Harand A (2007) Complex rearrangements are involved in Cephalanthera (Orchidaceae) chromosome evolution. Chromosome Res 15:931-943

Murashige T, Skoog F (1962) A revised medium for rapid growth and bio assays with tobacco tissue cultures. Physiol Plant 15:473-497

Murray BG (2005) When does intercytotypic C-value variation become taxonomically significant? Ann Bot 95:119-125

Nakazawa D, Kishimoto T, Sato T, Saito T, Amano J, Kuwayama S, Okuno H, Godo T, Watanabe Y, Han DS, Nakano M (2011) Genomic in situ hybridization (GISH) analysis of intergeneric hybrids in Colchicaceae. Euphytica 181:197-202

Navabi ZK, Stead KE, Pires JC, Xiong ZY, Sharpe AG, Parkin IAP, Rahman MH, Good AG (2011) Analysis of B-Genome chromosome introgression in interspecific hybrids of Brassica napus $\times$ B. carinata. Genetics 187:659-673

Schwarzacher T, Leitch A, Bennett M, Heslop-Harrison J (1989) In situ localization of parental genomes in a wide hybrid. Ann Bot 64:315-324

Sheu JJ, Yu TS, Tong WF, Yu SM (1996) Carbohydrate starvation stimulates differential expression of rice alphaamylase genes that is modulated through complicated transcriptional and posttranscriptional processes. J Biol Chem 271:26998-27004

Tang F, Chen F, Chen S, Wang X, Zhao H (2010) Molecular cytogenetic identification and relationship of the artificial intergeneric hybrid between Dendranthema indica and Crossostephium chinense by GISH. Plant Syst Evol 289:91-99

Yao XC, Ge XH, Chen JP, Li ZY (2010) Intra- and intergenomic relationships in interspecific hybrids between Brassica $(B$. rapa, $B$. napus) and a wild species B. maurorum as revealed by genomic in situ hybridization (GISH). Euphytica 173:113-120 